\title{
COMUNIDADE VIRTUAL E SUA INSERÇÃO NO PROCESSO EDUCACIONAL COMO FORMA DE AMPLIAÇÃO DO CAMPO DAS RELAÇÕES
}

\section{Rejane Machado}

\section{RESUMO}

Este trabalho tem como premissa demonstrar o uso de comunidade virtual como forma de ampliação do campo das relações em conformidade com o objetivo de ensinar e aprender. Para melhor entender a questão realizou-se levantamento bibliográfico da literatura a respeito do tema e posterior observação da comunidade objeto do estudo. A partir das leituras feitas e da análise da comunidade em seu período ativo foi possível perceber o entendimento do uso nessa comunidade virtual de aprendizagem e as questões que nortearam o seu fluxo. Fica claro que a tecnologia é a ferramenta que possibilita o incremento da comunidade como um instrumento potencializador da comunicação, mas, constata-se que sem o sentimento de pertencimento e o trabalho colaborativo a construção do conhecimento coletivo não atinge resultados satisfatórios.

\section{PALAVRAS CHAVES}

Comunidade virtual; Ensino-aprendizado; Acesso à informação

\section{VIRTUAL COMMUNITY AND THE INSERT IN THE EDUCATION PROCESS AS FORM OF AMPLIFICATION OF THE FIELD OF THE RELATIONSHIPS}

\begin{abstract}
This work has as premise to demonstrate virtual community's use as form of enlargement of the field of the relationships in accordance with objective of teaching and learning. To understand the subject it took place bibliographical rising of the literature regarding the theme and subsequent observation of the community object of the study. Starting from the readings and the community's analysis in it active period was possible to notice the understanding of the use in that virtual community of learning and the subjects that orientated it flow. It sure that technology is the tool that makes possible the community's increment as instrument potentialities of the communication, but, it is verified that without the concerning feeling and the collaboration work the construction of the collective knowledge doesn't reach satisfactory results.
\end{abstract}

\section{KEY WORDS}

Virtual community; Teaching-learning; Access the information 


\section{INTRODUÇÃO}

Nos primórdios as cartas era o mecanismo utilizado para passar ensinamentos entre os povos, mais adiante os cursos por correspondência foram criados com o objetivo de ensinar de forma não presencial. Na verdade a comunicação era lenta e nem sempre se tinha a garantia de que os documentos chegassem ao seu destino. Hoje, com as inúmeras possibilidades existentes seja através do uso de multimídia e dos meios eletrônicos essas atividades assumem outra conformação. O termo ciberespaço surgiu:

\footnotetext{
originalmente na novela de ficção científica Neuromante, de William Gibson*, é o nome por vezes usado para designar o espaço conceptual onde se manifestam palavras, relações humanas, dados, riqueza e poder dos utilizadores da tecnologia de comunicação mediada por computador. (REINGHOLD, 1996, p.18).
}

Neste sentido podemos entender o ciberespaço como uma ampla rede composta da infra-estrutura de informática e das tecnologias de telecomunicações, programas, interfaces e dados, que de forma integrada forma um ambiente dinâmico e interativo de troca de informações.

Portanto, o ciberespaço representa as novas formas de comunicação entre os indivíduos que são possíveis através do desenvolvimento e implantação de tecnologias da computação e de transmissão de dados.

É nesse ambiente da rede Internet que reside o volume crescente de produção de informação e conseqüente circulação de forma pulverizada. A questão é como acumular e de que forma organizar informações afins; e como pode acontecer a integração e compartilhamento desses conteúdos no domínio da educação. Em síntese, as comunidades virtuais, aqui descritas como: “...relações sociais formadas no ciberespaço [espaço virtual] através do contato repetido em um limite ou local específico (como uma conferência eletrônica) simbolicamente delineado por tópico ou interesse.” (FERNBACK; THOMPSON, 1995 apud PRIMO, 2005, p. 2).

Elas podem ser utilizadas como ambiente alternativo na busca da socialização do conhecimento. A criação de Comunidade Virtual possibilita a construção da inteligência coletiva, que se dá através da transformação de valores que facilitam a interação freqüente, da integração estabelecendo assim os laços de afeto entre os membros e o compartilhamento seja de informações, valores e experiências.

Este trabalho pretende contribuir para dar visibilidade do uso de comunidade virtual, como formas de: inovar métodos, conteúdo, novos formatos e estruturas do processo de 
ensino-aprendizado que recebendo a influência da incorporação das novas tecnologias de informação e comunicação, favorece a sua compreensão e utilização.

\section{O AMBIENTE DE APRENDIZAGEM INDIVIDUAL}

O ambiente virtual de aprendizado se caracteriza como o referencial de apoio ao ensino presencial, utilizando o educador da capacidade pedagógica aliada ao recurso disponível. Nessa nova realidade tais como, espaços virtuais e a busca do trabalho cooperativo, como sendo uma forma aprender onde o grupo atua junto, o educador passa a ser também o aprendiz em constante atualização, estimulando o hábito do auto-estudo, redesenhando modelos e processos para uma boa aprendizagem através de experiências, que são medidas e apontadas para a realização plena da educação.

A Internet possibilita o incremento e a ampliação das relações sociais com as novas formas de comunicação que estão disponíveis na rede, tais como, chats, fóruns, blogs, videoconferências e outros, onde os limites espacial e temporal inexistem.

Por outro lado, as Instituições que têm como meta educar que em sua forma clássica é o espaço onde reside o centro do saber, passa por transformações em sua infra-estrutura, nas relações humanas ‘professor-aluno’ ou ‘educador-aprendiz’ em seus novos papéis, buscando se adaptar ao novo e ao mesmo tempo buscando a renovação no ato de ensinar onde o individual se contrapõe ao coletivo; a competição à colaboração, permeada pela interação e a integração.

Com isso emerge a possibilidade de criação dos ambientes virtuais de aprendizagem, que para melhor situar neste estudo, denominamos de 'ciberespaço', termo definido no início do trabalho e de 'e-learning' que é uma nova modalidade utilizada para ensinar e treinar aliada aos recursos tecnológicos, seja por meio da Internet ou de redes fechadas.

Nesse ambiente a informação e a comunicação estão à disposição, possibilitando o acesso aos ambientes onde se dá à troca de conhecimento, o compartilhamento de informações, de práticas individuais, possibilidades de desenvolvimento de novos métodos, aonde o 'ir e vir' são constituintes da formação da inteligência coletiva.

Para melhor entendimento dessa construção usamos o conceito de Pierre Lévy sobre inteligência coletiva, como sendo: “...uma inteligência distribuída por toda parte, incessantemente valorizada, coordenada em tempo real, que resulta em uma mobilização efetiva das competências.” (LÉVY,1998, p.38). 
A interação, integração são algumas das características básicas para essa construção, devemos para tal, utilizar algumas estratégias, tais como: buscar desenvolver a participação comunitária como elemento essencial para que o indivíduo se sinta pertencendo ao ambiente, com certa flexibilidade e respectiva valorização dos membros do grupo; outra é fazê-lo sentirse motivado a participar seja de forma síncronas ou assíncronas, tanto como receptor quanto emissor nesse processo, e, por fim o estímulo da capacidade de cooperar de forma efetiva e criativamente, construindo relações positivas que expandam o comprometimento com o objeto e a integração ao ambiente.

As circunstâncias criadas e trabalhos bem elaborados com relações fortes geram em cada ambiente condição de se acontecer uma metamorfose, ou seja, uma transformação do indivíduo e do grupo como um todo. Seria como um espelhamento uníssono em torno de um objetivo ou meta. A participação garantida no acolhimento do ambiente, boas práticas nas relações entre os membros seja de um para todos, todos para todos, aprendendo, se desenvolvendo, se fortalecendo coletivamente, buscar esse permeio no ambiente são os passos essenciais para bons resultados. Teixeira (2005) considera que no ambiente escolar:

deve haver uma tensão entre o saber e o saber-fazer da dimensão conteúdo e o saber-fazer que denominamos acadêmica que trata exatamente das competências transversais para o ofício do aluno, que são atitudes hábitos que o levam a aprender a aprender, (TEIXEIRA, 2005, p.23).

O processo de transferência em sua nova forma vem de duas vertentes: a primeira é o professor com sua nova experiência e a segunda é a demanda do aluno com uma enxurrada de informações que são coletadas na rede e sua necessidade de conhecer. Nessa nova tarefa de ensinar e aprender; novos ambientes surgiram para serem testados, aprovados e sedimentados. Ambientes esses que vieram para ampliar entre outras coisas, a divulgação e o acesso.

Segundo Azevêdo (2005) comunidades virtuais de aprendizagem se constituem não com uma: “identificação local, como no tradicional conceito sociológico de comunidades. É uma comunidade de interesse. É localizada por um endereço sim, mas um endereço lógico e não físico. Essas comunidades virtuais são de aprendizagem.” (AZEVÊDO, 2005, p. 21).

Nesse ambiente que é único com os atores representados pelo professor com seu novo papel de mediador e pelo aluno atuando de forma clara e franca e pelo fato de não serem passivos assumem o papel de receptores e emissores; ensinam e aprendem em conjunto, construindo assim o conhecimento coletivamente, “... os participantes do processo educativo 
tornam-se co-autores e co-criadores de um conhecimento que está em constante transformação;” (DIAS; MOURA, 2006, p.10).

\section{ESTUDO DE CASO DE UMA COMUNIDADE VIRTUAL NO ENSINO SUPERIOR}

O presente estudo tem um caráter descritivo. Com esse objetivo o método para a sua consecução foi norteado pelos seguintes instrumentos: levantamento bibliográfico acerca das questões envolvidas nesse estudo, seguido de identificação e seleção de comunidade criada em ambiente de aprendizado e por fim o mapeamento e análise do uso da comunidade selecionada em seu período ativo.

Utilizou-se para estudo comunidade criada no site de relacionamentos. Optou-se pelo Orkut inicialmente pela disponibilização via Internet e facilidade de acesso. Segundo Castilho (2005, p.1) o Orkut é: “uma das novas ferramentas que está sendo atualmente utilizada como meio de comunicação e troca de informações entre professores, educadores e estudantes.” (CASTILHO, 2005, p.1).

Para a autora o modelo de rede do Orkut foi inspirado na teoria 'Mundo pequeno' de Stanley Milgram, 1967 nos EUA que constatou por meio de pesquisa que estamos a apenas a seis graus de separação de um outro grupo de pessoas, e que:

...as conexões entre todas as pessoas formam pequenas redes interconectadas, não maior que seis ou sete pessoas. É possível duas pessoas que não se conhecem estabelecerem contato entre elas através de uma pessoa de seu conhecimento que indique uma nova pessoa e assim sucessivamente, formando uma pequena cadeia. (CASTILHO, 2005, p.7).

Outro quesito importante é que o Orkut é um serviço livre de rede social que tem, segundo estatísticas de uso do serviço, o Brasil como o país com o maior número de membros, estando entre os dez países que mais utiliza a rede. O ranking de utilização de acordo com dados atualizados em torno de setenta por cento de conectados de toda a rede. $\mathrm{O}$ objetivo desse serviço é prover a criação e manutenção de relacionamentos no espaço não real. “A frase que comumente é utilizada para explicar por que uma pessoa deseja se cadastrar no Orkut é de que todo mundo está lá.” (CASTILHO, 2005, p.8)

A partir do cadastro no site o participante na rede pode pesquisar amigos e comunidades utilizando ferramenta de busca que é de fácil utilização. Essas ferramentas possuem diversas opções de filtros para refino da busca. Podem-se também criar comunidades virtuais classificando-as nas categorias determinadas e dispostas no site. 


\section{Área Temática: Educação, Comunicação \& Tecnologia}

O serviço dispõe de funções que auxiliam no controle e prevenção de mensagens spam, possui também estatísticas de uso e as atualizações do site são feitas diariamente.

Como o objetivo primordial do Orkut é a rede de amigos, os serviços básicos oferecidos se resumem em duas vertentes: a primeira se dá a partir das comunidades criadas com fóruns, mensagens e eventos; e a segunda fora do ambiente de comunidades o serviço de recados, de depoimentos e de disponibilização de fotos. As informações descritas foram retiradas do site no endereço: http://www.orkut.com, no período do estudo.

\section{A AMOSTRA}

A comunidade está categorizada em 'Alunos e Escolas', essa comunidade é do tipo 'mediada', ou seja, com acesso permitido mediante autorização do mediador que é o seu criador, e com fórum não-anônimo. Essas escolhas são formas de garantir a credibilidade da proposta da comunidade criada.

O objetivo desta comunidade virtual criada em 22 de abril de 2006, pelo docente da disciplina 'Políticas Educacionais’ do Curso 'Docência do Ensino Superior', é de ser um espaço de reflexão sobre as Políticas Educacionais no Brasil - Temas, com enfoque em temáticas em conformidade com o acordado no decurso da disciplina dada.

Quando a proposta foi colocada em sala de aula buscou-se conhecer se teria algum aluno excluído digitalmente e somente um aluno entre os 48 não possuía computador e não tinha acesso a Internet no ambiente de trabalho, representando menos de $1 \%$ da população. Esse aluno ficou com a alternativa de usar a tecnologia existente na infra-estrutura da Instituição de Ensino ou de obter a parceria de um colega para fazer os trabalhos de grupo.

Ocorreu também resistência à proposta, demonstrada no decurso da aula, onde seis alunos se manifestaram contrários à iniciativa de desenvolver trabalhos em grupo da disciplina através do uso de comunidade virtual. As justificativas foram as mais variadas, tais como: não tenho tempo; não está incluído no programa do curso; não gosto da Internet, entre outros. Após as manifestações obteve-se consenso da participação da turma nos trabalhos sob essa nova forma, ou seja, o desenvolvimento e a postagem por e-mail. A proposta possibilitou a realização deste estudo.

O estudo da dinâmica da comunidade foi iniciado tendo como base a lista de presença da disciplina para identificar a população da amostra. Na listagem constam 48 alunos matriculados na disciplina Políticas educacionais no Curso de Docência do Ensino Superior 
da Faculdade Candido Mendes - Campus Centro II. Os inscritos na disciplina são os membros potenciais da comunidade virtual.

Com a comunidade virtual criada iniciou-se o processo de adesão de membros e participação no fórum de acordo com a primeira temática. Dos 49 potenciais membros (48 alunos e mais o docente), 26 alunos da disciplina solicitaram sua adesão, sendo que os participantes do sexo feminino predominaram (22) e (4) do sexo masculino.

No primeiro mês de observação da comunidade virtual criada 33 membros aderiram ao espaço sendo que seis membros são oriundos de outras fontes de relacionamento do mediador. Com a adesão de (55\%) de alunos conforme representado abaixo, pode-se constatar que as ferramentas de comunicação que estão disponíveis na Internet são utilizadas pelos usuários sejam sob a forma de comunidades virtuais, chats, fóruns etc.

\section{RESULTADOS}

A observação do comportamento dos usuários da comunidade virtual possibilitou a análise das adesões nos seus diversos níveis e participação efetiva para a identificação do conjunto de usuários que compuseram os laços fortes da comunidade no período analisado.

Por não ter acontecido adesão total o espaço onde reside à interação, por ser o espaço público e dinâmico dos fóruns, foi utilizado de forma diferenciada. Algumas participações se deram via um membro inscrito que representou o grupo, porém, as discussões dos temas propostos foram feitas através do espaço privado, ou seja, o contato um a um utilizando o email e somente o trabalho final foi colocado nos respectivos fóruns.

Os membros que mediaram seus grupos e participaram ativamente dos fóruns foram num total de dez incluindo o mediador, esses, podem ser considerados os membros com laços fortes dessa comunidade virtual. Três participantes de um grupo apesar de não terem conseguido se registrar no site; mesmo assim participaram através de membros do grupo, participantes da rede, totalizando mais três membros nesse universo com participação indireta.

Os membros inscritos que não participaram ativamente dos fóruns foram um total de 17 pessoas. Esses podem ser classificados de membros passivos que entram em uma comunidade, monitoram, mas, a princípio não contribuem, são observadores, mas, usufruem o conteúdo disponibilizado.

O fórum teve os seguintes tópicos para discussão: o primeiro foi 'o professor ideal', o segundo foi ‘autonomia universitária’ o terceiro e último tema foi ‘reforma universitária’. 
A dinâmica do fórum não foi bem estruturada, talvez pelo fato da comunidade ter sido recentemente criada, bem como os temas serem novos para a maior parte dos membros. $\mathrm{O}$ total de intervenções no fórum foi onze sendo que três dessas partiram do mediador e as restantes foram dos grupos.

A observação se deu a partir da data de criação da comunidade até o término da disciplina em fins de maio. Entretanto o fórum continuou ativo até a entrega dos trabalhos finais da disciplina. Ficou bem claro na comunidade analisada quem são os participantes ativos e os passivos.

Considerando o foco de interesse a princípio essa comunidade tem a característica de efemeridade, com um ciclo de vida curto e pré-determinado. Isto não quer dizer que a mesma seja descontinuada. As adesões externas sinalizam que mesmo não sendo uma comunidade pública, outros membros podem ser agregados pelo foco de interesse e a comunidade pode se manter viva e dinâmica.

Pelo próprio objetivo da comunidade a tendência é não aprofundar seus laços, portanto, não conseguindo ampliar seu capital social. Entretanto, não deixa de ser uma iniciativa importante como um ferramental de apoio ao ensino presencial.

Entretanto, esse ambiente perde as características de comunidade virtual voltada para a construção coletiva do conhecimento de uma forma mais sedimentada, passando a ser um espaço que pode ser o repositório de informações para um grupo de pessoas unidas pelos interesses colocados anteriormente e pelos laços criados nas aulas presenciais e também para cumprimento do acordado entre professor-aluno.

Este trabalho possibilitou identificar melhor a nova dinâmica que demanda para o educador a partir de aluno antenado nas novas tecnologias que exige uma atenção que pode estar ancorada em alguns modelos clássicos, mas, reformulada para se coadunar com a nova geração que têm a capacidade de se interessar por diversos temas com a mesma agilidade com que acessam a rede.

A atuação de forma colaborativa é a tendência a se firmar como uma condição 'sine qua non', para que a construção coletiva do conhecimento não dê lugar à simples reprodução do mesmo. Outro fator importante é a valorização do conhecimento empírico do aprendiz e sua necessidade de respostas as suas demandas. Nesse novo ambiente o atributo de educador / mediador se consolida e apresenta desafios para esse educador que tem que aprender esse 'novo agir' por esforço próprio como e fazer acontecer a sua metamorfose. 
Nesse contexto o ‘vis-a-vis’ que contem em si os atributos de espaço físico e tempo na forma clássica de ensinar-aprender e o virtual que é des-territorializado e atemporal se intercalam na construção do conhecimento de forma criativa e inovadora.

Outros pontos relevantes foram levantados para o entendimento do uso de comunidade virtual de aprendizagem. Uma das questões importantes é que sem o sentimento de pertencimento àquela comunidade, o aprendiz não atua ativamente, não tem iniciativa, fica passivo diante das informações e se esquiva das discussões.

Não se pode perder de vista de que comunidades virtuais não é "um fenômeno tecnológico. É proporcionado pela tecnologia mais é fundamentalmente sociológico.” (AZEVÊDO, 2005, p.21). A simples oferta de ferramentas para ambientes de comunidade virtuais não define o seu uso. Para que a comunidade se torne realidade, é preciso que o grupo esteja focado na discussão do objeto e que o objeto seja parte de um objetivo - com início, meio e fim - e que seja parte integrante e importante do ambiente do ensino-aprendizado de cada participante, para que se possa desenvolver e concluir tal como uma reciclagem orgânica em que o velho adquire uma nova roupagem e novo uso.

Cabe considerar que a tecnologia disponível por si só não basta, não é suficiente para levar adiante um projeto de construção coletiva do conhecimento. A tecnologia para ambientes de comunidade virtual é, na verdade, um instrumento que potencializa a comunicação e a interação entre indivíduos. Entretanto as ferramentas que constituem as comunidades virtuais pode ser a solução para a construção de ambiente onde se possam desenvolver novas experiências, acompanhamento mais dinâmico do desenvolvimento dos alunos, bem como a disponibilização rápida de conteúdos, temáticas ou questões abordadas em sala de aula, visando um aprofundamento das discussões pelo coletivo e a sedimentação do que foi ensinado.

\section{REFERÊNCIAS}

AZEVÊDO, W. Muito além do jardim de infância: temas de educação online. Rio de Janeiro: Armazém Digital, 2005.

CASTILHO, D. Novas tecnologias de ensino e aprendizagem: a Internet, a tecnologia e os ambientes virtuais. Disponível em: http://www.oolhodahistoria.ufba.br. Acesso em: 8 jan. 2007.

DIAS, A. A. C.; MOURA, K. S. Cultura na/da rede: refletindo sobre os processo educativos sob a ótica bakhtiniana. Ciência \& cognição. n.9, p.1-14, 2006. Disponível em:

http://www.cienciaecognição.org/. Acesso em: 18 jan. 2007.

(C) ETD - Educação Temática Digital , Campinas, v.9, n.1, p.39-48, dez. 2007 - ISSN: 1676-2592. 


\section{Área Temática: Educação, Comunicação \& Tecnologia}

LÉVY, P. Inteligência coletiva. São Paulo: Loyola, 1998. 214p.

MORIN, E. Os sete saberes necessários à educação do futuro. Brasília: UNESCO, 2005.

ORKUT. [site]. Disponível em: http://www.orkut.com/. Acesso em: 2 jun. 2006.

PRIMO, A. F. T. A emergência das comunidades virtuais. Disponível em:

http://lec.psico.ufrg.br/ Acesso em: 12 maio 2005.

RHEINGOLD, H. A comunidade virtual. Lisboa: Gradiva Publicações, 1996. 367p.

SANTOS, E. O. A construção de ambientes virtuais de aprendizagem. Disponível em: http://www.anped.org.br/26/trabalhos/. Acesso em:18 jan. 2007.

TEIXEIRA, E. As três metodologias: acadêmica, da ciência e da pesquisa. Petrópolis: Vozes, 2005. 203p.

TORRES, R. M. Comunidade de aprendizagem: a educação em função do desenvolvimento local e da aprendizagem. Disponível em: http://www.fronesis.org/ Acesso em: 18 jan. 2007. 